Pesq. Vet. Bras. 29(1):45-51, janeiro 2009

\title{
Trombectomia com cateter de Fogarty no tratamento da tromboflebite jugular experimental em eqüinos ${ }^{1}$
}

\author{
Carlos A. Hussni ${ }^{\star}$, Peterson T. Dornbusch ${ }^{3}$, Winston B. Yoshida ${ }^{4}$, Ana L. G. \\ Alves $^{5}$, José L. M. Nicoletti ${ }^{5}$, Maria J. Mamprim ${ }^{6}$ e Luiz C. Vulcano ${ }^{6}$
}

\begin{abstract}
Hussni C.A., Dornbusch P.T., Yoshida W.B., Alves A.L.G., Nicolett, J.L.M., Mamprim M.J. \& Vulcano L.C. 2009. [Thrombectomy with Fogarty's catheter as a treatment of induced jugular thrombophlebitis in horses.] Trombectomia com cateter de Fogarty no tratamento da tromboflebite jugular experimental em eqüinos. Pesquisa Veterinária Brasileira 29(1):45-51. Departamento de Cirurgia e Anestesiologia Veterinária, Faculdade de Medicina Veterinária e Zootecnia, Universidade Estadual Paulista, Botucatu, SP 18618-000, Brazil. E-mail: cahussni@fmvz.unesp.br

Thrombosis of jugular vein is a common problem in the equine medicine, implying frequently in fatal outcomes. The diagnosis is relatively simple, based on the clinical findings, angiographics images and ultrasonographycs. The therapeutic employed to a large extent of the cases is unsatisfactory. The purpose of this study was to evaluate the applicability of the thrombectomy with Fogarty's catheter in horses. This technique is routinely used in medicine, in the reestablishment of the vascular perviousness. Ten horses were allocated in two groups (five animals each) and induced to an unilateral thrombosis of right jugular vein, through the surgical access and an application of stenotic suture and glucose $50 \%$ injection. In the control group evolution of the thrombophlebitis without any therapeutical intervention was evaluated. The animals of the treatment group were submitted to the thrombectomy with Fogarty's catheter. General clinical parameters were analyzed at the moment of the preinduction (MPRE), induction of thrombosis (MTI), and at the $10^{\text {th }}$ day of thrombosis evolution (M10). The procedure induced thrombophlebitis that completely obstructed a segment of the jugular vein in all animals. In the animals of the control group, the thrombus totally obstructed the vascular lumen until the end of the period of evaluation, and parotid edema and vascular dilated, cranial to the thrombophlebitis of jugular vein were observed. The treatment group presented all veins pervious in the end of the experiment, with total remission of the clinical signs, confirmed by angiographic and ultrasonographic examinations. So far, it was concluded that the technique of thrombectomy with Fogarty's catheter was effective in removal of the thrombosis obstruction experimentally induced in the jugular vein.
\end{abstract}

INDEX TERMS: Horses, jugular vein, thrombophlebitis, thrombectomy, Fogarty's catheter.
RESUMO.- Trombose da veia jugular é problema freqüente na medicina eqüina, implicando muitas vezes em conseqüências fatais. $\mathrm{O}$ objetivo deste trabalho foi avaliar em eqüinos a aplicabilidade da trombectomia com cateter de Fogarty, técnica rotineiramente empregada pela medicina humana, no restabelecimento da perviedade vascular. Foram utilizados 10 eqüinos divididos em dois grupos de cinco animais, em que se induziu a trombose da veia jugular direita, através do acesso cirúrgico à veia e aplicação de sutura estenosante e injeção de glicose a 50\%. No grupo controle avaliou-se a evolução da tromboflebite sem qualquer tipo de intervenção terapêutica. Os animais 
do grupo tratado foram submetidos à trombectomia com cateter de Fogarty. Foram avaliados os parâmetros clínicos gerais, regionais, ultra-sonográficos e angiográficos, nos momentos pré-indução (M-PRÉ), indução da trombose (MTI) e 10 dias de evolução da trombose (M10). A técnica empregada induziu a tromboflebite, que obstruiu completamente um segmento da veia jugular de todos os animais. Os animais do grupo controle mantiveram os trombos obstruindo totalmente o lume vascular até o final do período de avaliação, sendo que avaliações regionais mostraram principalmente o edema parotídeo e o ingurgitamento vascular, cranial à tromboflebite da veia jugular. O grupo tratado apresentou as veias jugulares pérvias ao final do experimento, confirmadas pelos exames ultrasonográficos e angiográficos, com remissão total dos sinais clínicos. Concluiu-se que a técnica da trombectomia com cateter de Fogarty foi eficiente na desobstrução da veia jugular submetida à trombose experimental.

TERMOS DE INDEXAÇÃO: Eqüinos, veia jugular, tromboflebite, trombectomia, cateter de Fogarty.

\section{INTRODUÇÃO}

Trombose é a formação intravascular de coágulo obstrutivo ao fluxo sanguíneo (Montenegro \& Franco 1999), podendo ser desencadeado por três tipos de alterações que compreendem a Tríade de Virchow, sendo a alteração da parede vascular, a alteração do fluxo sanguíneo e a alteração dos componentes do sangue (Maffei et al. 2002).

A tríade de Virchow serve de base em estudos para a indução da trombose, em que a alteração na parede vascular pode ser obtida experimentalmente considerando-se o trauma causado por clampes (Underwood et al. 1993), lesão química do endotélio (Silveira et al. 2001), lesão endotelial térmica através do laser (Imbault et al. 1996), aplicação de corrente elétrica (Sigel et al. 1994), substituição de um segmento venoso por um segmento sintético (Van Zyl et al. 2000) ou, ainda, na substituição por segmentos homólogos antigênicos (Hupkens \& Cooley 1997).

Quando a base do modelo experimental é a alteração no fluxo sanguíneo o modelo mais utilizado é a ligadura do segmento venoso, em que se deseja induzir a trombose (Feuerstein et al. 1999, Henke et al. 2001) ou a introdução de objetos intraluminais, provocando a estase sanguínea (Lin et al. 2001).

$\mathrm{Na}$ seleção de um modelo experimental devem ser consideradas as diferenças estruturais e funcionais entre veias e artérias, o calibre dos vasos e os diferentes vasos utilizados como modelos experimentais. Em estudos, nem sempre é possível se utilizar a espécie de interesse clínico. As espécies mais utilizadas para experimentação, em cirurgia vascular, são cães coelhos, ratos, suínos, primatas e humanos (Sigel et al. 1994, Quarmby et al. 1996, Van Zyl et al. 2000, Silveira et al. 2001), não existindo um modelo experimental para estudo da trombose nos eqüinos. Além de conhecer os mecanismos de evolução dos trombos, os modelos experimentais buscam testar os métodos terapêuticos existentes. A terapêutica utilizada nas tromboses deve ter como objetivos a prevenção da propagação do trombo e da embolia pulmonar, a restauração da perviedade vascular com a prevenção da recorrência e minimizar os sintomas pós-flebite (Dornbusch et al. 2000, Maffei et al. 2002).

$\mathrm{Na}$ espécie eqüina os principais vasos acometidos de trombose são a veia jugular, os vasos podais e a circulação mesentérica, sendo que todas essas situações incorrem em riscos para os pacientes (Divers 2003). A tromboflebite jugular decorre, principalmente, de repetidas punções, associadas à falta de assepsia e imperícia no procedimento (Dornbusch et al. 2000). O estudo da trombose de jugular eqüina está focado na utilização de cateteres, em relatos de casos clínicos (Bayly \& Vale 1982, Morris 1989, Spurlock \& Spurlock 1990, Gardner et al. 1991, Ettlinger et al. 1992, Warmedam 1998); na detecção do potencial trombogênico de fármacos que agridem a superfície endotelial (Traub-Dargatz \& Dargatz 1994) e nos distúrbios da coagulação que acompanham os pacientes com cólica (Baxter et al. 1991, Topper \& Prasse 1998).

Este trabalho teve por objetivos estudar a indução experimental da tromboflebite jugular em eqüinos e aplicar o tratamento cirúrgico pela trombectomia com cateter de Fogarty para o restabelecimento da perviedade jugular.

\section{MATERIAL E MÉTODOS}

Foram utilizados dez eqüinos adultos, de ambos os sexos, com 350 quilos de peso médio saudáveis, mantidos em baias individuais, durante todo o experimento, alimentados com feno de coast-cross e concentrado comercial ( $1 \%$ do peso vivo ao dia, dividido em duas vezes) e água ad libtum. Todos os animais tiveram a veia jugular direita submetida à trombose experimental, sendo então distribuídos aleatoriamente em dois grupos de cinco animais. O grupo tratado teve os animais submetidos à trombectomia com cateter de Fogarty após a indução da trombose e foram avaliados durante dez dias. O grupo controle teve os animais acompanhados pelo mesmo período, sem tratamento.

Antes da indução da tromboflebite (M-PRÉ) foi confirmada a higidez da veia jugular nos dez eqüinos, pelos exames físicos, ultra-sonográficos e venográficos. A indução da tromboflebite seguiu a tranqüilização com xilazina $(1 \mathrm{mg} / \mathrm{kg})$ (Sedazine, Fort Dodge Saúde Animal, Campinas, SP, Brasil) via intravenosa, na veia jugular esquerda e realização da tricotomia na região cervical direita, sobre a veia jugular. Em seguida realizou-se a anestesia local com lidocaína 2\% (Xylestesin, Cristália, Itapira, $\mathrm{SP}$, Brasil) na região da veia jugular direita no terço médio do pescoço. Foi realizada a incisão de pele de dez centímetros, em que a veia jugular foi exposta, sendo aplicadas duas pinças vasculares tipo De Bakey, numa distância de cinco centímetros entre as mesmas. Caudalmente às pinças, foi aplicada uma ligadura temporária envolvendo a veia jugular, permitindo o garroteamento desta com fio de seda 2 trançado (JP, Ribeirão Preto, SP, Brasil) que, aplicado através da pele, circundou a veia jugular, permitindo que o ponto fechado mantivesse 0 garroteamento proximal às pinças e deste modo apresentouse o nó exposto sobre a pele.

Na seqüência foi introduzido um escalpe (Plascalp, Feira de 
Santana, BA, Brasil) no segmento vascular isolado, para a retirada do sangue do lúmen, entre os clampes, seguido da irrigação com solução de glicose a 50\% (JP, Ribeirão Preto, SP, Brasil), suficiente para dilatar o vaso. Após 15 minutos as pinças foram liberadas, e o subcutâneo foi suturado em padrão simples contínuo com fio de poliglactina 2-0 (Vicril, Ethicon, Johnsons \& Johnsons, São José dos Campos, SP, Brasil). A pele foi suturada de modo simples contínuo com fio de nylon 2-0 (JP, Ribeirão Preto, SP, Brasil). A veia foi mantida obstruída durante 72 horas, quando o fio de seda remanescente, que mantinha a oclusão, foi retirado. Deste modo, a indução da trombose ocorreu em período de 72 horas, compreendendo a cirurgia até a remoção do garrote representado pelo fio de seda, correspondendo ao momento de tromboflebite induzida (MTI). O acompanhamento de cada animal foi realizado diariamente, correspondendo, após o MTI, aos momentos do $1^{\circ}$ ao $10^{\circ}$ dia (M1 a M10).

Os animais do grupo tratado, no primeiro dia após confirmada a tromboflebite jugular oclusiva por avaliação clínica e ultrasonográfica, foram submetidos à trombectomia realizada sob anestesia geral inalatória de rotina. Procedeu-se a anti-sepsia e montagem do campo cirúrgico. Realizou-se na pele a incisão de aproximadamente cinco centímetros de comprimento, sobre a veia jugular direita, na região cervical caudal ao trombo, sendo feita a divulsão dos planos teciduais e o isolamento da veia jugular. Foram passadas fitas cirúrgicas (Fita Umbilical-Ethicon, Johnsons \& Johnsons, São José dos Campos, SP, Brasil) proximal e distalmente, estabelecendo-se a distância de quatro centímetros entre as fitas, para permitir o controle do fluxo sanguíneo. Procedeu-se a flebotomia jugular longitudinal de aproximadamente $2 \mathrm{~cm}$, entre as fitas vasculares. Introduziu-se o cateter de Fogarty (Cateter de Fogarty 7F, Edwards Lifesciences Macchi, São Paulo, SP, Brasil), em direção cranial. (Fig.1)

A graduação presente no cateter Fogarty permitiu o controle da introdução do cateter que, passando através do trombo, foi posicionado com a extremidade colocada cranial à obstrução, com posterior distensão do balão com solução fisiológica. Com o balão distendido, o cateter ao ser tracionado removeu o trombo. A manipulação de introdução do cateter, distensão do balão e retirada do trombo foi repetida várias vezes, até apresentar sangramento abundante, controlado com as fitas cirúrgicas. Removido o trombo, seguiu-se a sutura da jugular com fio de polipropileno 6-0 (Prolene-Ethicon, Johnsons \& Johnsons, São José dos Campos, SP, Brasil), em padrão

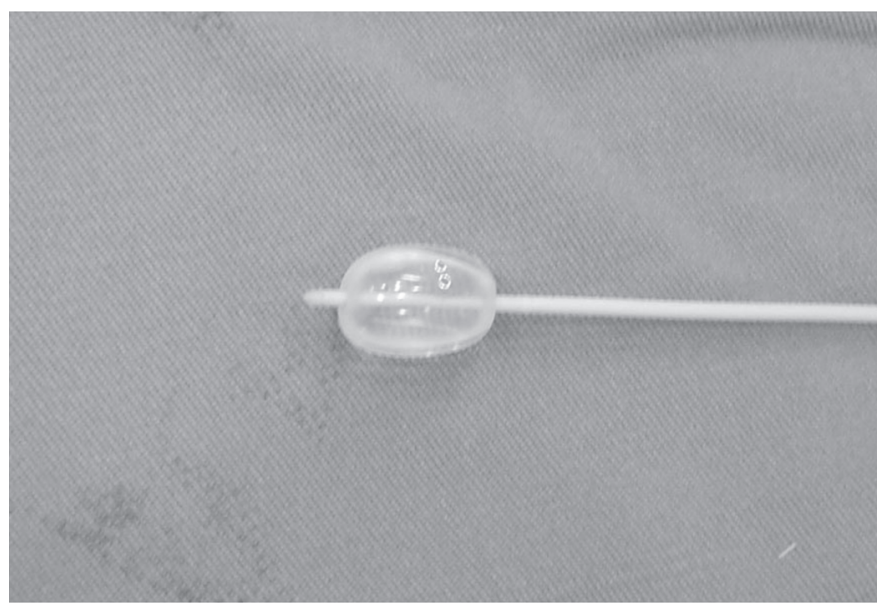

Fig.1. Extremidade do cateter de Fogarty no modo para remoção do trombo com o balão distendido.

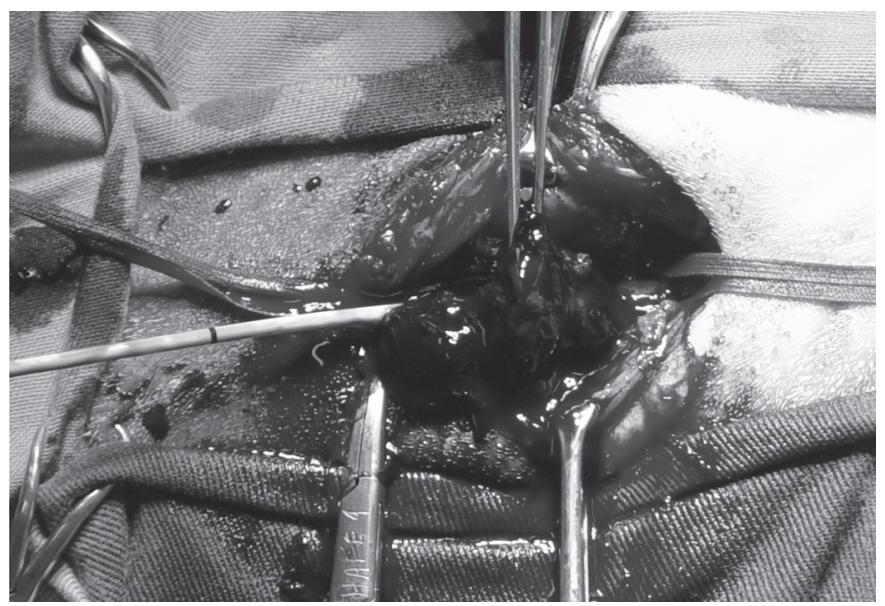

Fig.2. Remoção do trombo com o cateter de Fogarty.

simples contínuo abrangendo todos os planos da parede vascular. O tecido subcutâneo foi suturado com padrão contínuo simples, com fio poliglactina 2-0. A sutura da pele foi contínua simples com fio de nylon 2-0 monofilamentar. A Figura 2 mostra a remoção do trombo.

No período pós-operatório os pacientes submetidos à trombectomia receberam heparina (100 UI/kg), por via subcutânea duas vezes ao dia (Moore \& Hinchcliff 1994), durante dez dias. Aplicaram-se, ainda, penicilina benzatina (40.000 UI/ kg) (Pentabiótico Veterinário, Fort Dodge, Campinas, SP, Brasil), via intramuscular, em duas doses com intervalo de 72 horas, e flunixina meglumina (Flumedin, Jofadel, Varginha, MG, Brasil), $1 \mathrm{mg} / \mathrm{kg}$ duas vezes ao dia, durante cinco dias, por via intramuscular. $\mathrm{O}$ curativo local foi realizado diariamente com álcool iodado $(5 \%)$, até a retirada dos pontos no $10^{\circ}$ dia de pósoperatório. (Fig.2)

As avaliações físicas (gerais, regionais e locais) foram realizadas diariamente, buscando-se observar alterações à inspeção e à palpação no local da cirurgia, como: edema, seroma, aumento de temperatura e sensibilidade dolorosa. 0 fluxo sanguíneo jugular no sentido crânio-caudal, passando pela região na qual houve a formação do trombo, foi estimado com o garroteamento por pressão digital da veia na entrada do tórax, proximal à região do trombo, visando observar o preenchimento do segmento venoso acima do garroteamento. Considerou-se, ainda, a ocorrência de edema nas regiões frontal, palpebral, supra-orbitária, massetérica e parotídea.

As avaliações ultra-sonográficas (Aloka-SSD 900, Japan) e venográficas da veia jugular direita foram realizadas em todos os animais de ambos os grupos, em três momentos: imediatamente antes da indução da trombose (M-PRÉ), no terceiro dia da indução da trombose, após a retirada do fio estenosante (MTI) e no $10^{\circ}$ dia após a indução da tromboflebite (M10). Nas avaliações ultra-sonográficas foram observados os aspectos de regularidade do fluxo sanguíneo nas porções cranial, na região do trombo e caudal a este, bem como as características individuais dos diferentes segmentos. Consideraram-se os seguintes critérios: presença de fluxo espontâneo, presença e características do trombo e compressibilidade venosa frente à pressão exercida pelo transdutor do ultra-som (Raghavendra et al. 1986). As venografias foram procedidas com o aparelho portátil (FNX - CTI 90 Plus-Electra, Rio de Janeiro, RJ, Brasil), posicionado com projeção látero-lateral da esquerda para a di- 
reita, com chassi contendo filme radiográfico 30x40cm (Kodak, Manaus, AM, Brasil) colocado sobre a veia jugular direita. A técnica radiográfica utilizou 70 kilovolts, três miliamperes por segundo e $90 \mathrm{~cm}$ de distância entre o chassi e a ampola radiográfica. Foi aplicado o contraste angiográfico com iohexol (Omnipaque, Sanofi Winthrop, Rio de Janeiro, RJ, Brasil), no volume de $20 \mathrm{ml}$ por aplicação, na veia jugular cranial à trombose seguido de imediato disparo radiográfico. Após 5 minutos foram repetidas as radiografias, sem uma reaplicação de contraste. As radiografias identificaram a perviedade vascular, presença ou ausência de fluxo através do segmento acometido de trombose e a presença e configuração dos vasos colaterais.

\section{RESULTADOS}

A técnica desenvolvida para a indução experimental de tromboflebite da veia jugular, permitiu a indução do trombo na veia jugular direita, nos dez animais estudados, obstruindo completamente o segmento do terço médio da veia jugular.

Os parâmetros clínicos gerais mantiveram-se normais em todos os animais, de ambos os grupos, durante todo o experimento. Induzida a tromboflebite, nos exames clínicos regionais constatou-se ingurgitamento da veia jugular no segmento cranial à região com trombose e nas veias linguofacial e maxilar, em todos os animais, permanecendo até o M10 nos animais do grupo controle. Nas regiões parotídea, massetérica e supra-orbitária observou-se o aumento de volume bastante intenso nas primeiras 12 horas do início da indução da tromboflebite, mostrando diminuição após as 24 horas. Nos animais do grupo controle, após o MTI, o edema nas diferentes regiões cefálicas regrediu lentamente até o M10, onde permaneceu discreto em três animais. No grupo tratado o aumento de volume nas regiões parotídea, supra-orbitária e massetérica e o ingurgitamento venoso do segmento cranial da jugular e das veias maxilar e linguofacial desapareceram completamente 24 horas após a trombectomia. Ao término do experimento (M10), os animais tratados não apresentaram alterações circulatórias de cabeça ou pescoço.

Foi observado discreto aumento de volume no local da tromboflebite. À palpação observou-se enrijecimento da veia jugular neste local. Estas alterações permaneceram até o final do período de avaliação nos animais do grupo controle e até a desobstrução cirúrgica no grupo tratamento.

A trombectomia com o cateter de Fogarty promoveu remoção do trombo oclusivo, em partes, em todos os cinco animais do grupo tratamento, permitindo o restabelecimento do fluxo sanguíneo no segmento desobstruído.

O exame ultra-sonográfico realizado no momento de indução da tromboflebite (MTI), mostrou a presença de trombo heterogêneo de menor ecogenicidade, obstruindo totalmente o lume do segmento vascular, em todos os dez animais estudados (Fig.3). $\mathrm{O}$ trombo presente mantinha a distensão local da veia jugular e seu formato não se alterava frente à compressão com o transdutor. Observou-se, em todos os animais, a área de estenose caudal ao trombo, provocada pela sutura previamente removida e um discreto acúmulo de líquido no tecido subcutâneo. No segmento cranial foi possível observar uma inversão do fluxo sanguí-

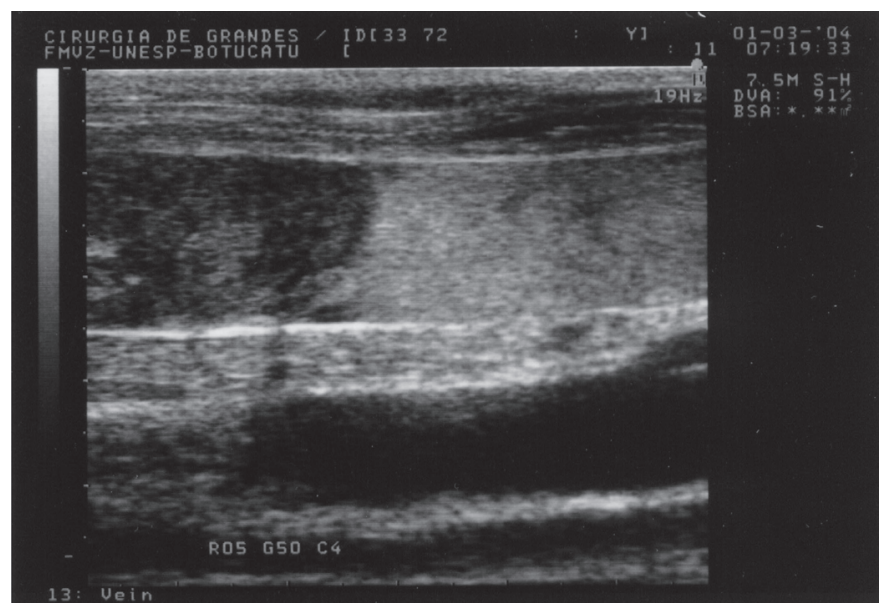

Fig.3. Aspecto do exame ultra-sonográfico da jugular no momento da tromboflebite induzida (MTI), com o trombo obstruindo completamente a veia jugular.

neo na veia linguofacial, que permitia a drenagem do sangue proveniente da veia maxilar, em cinco animais. Nos demais, o sangue era drenado através de vasos colaterais, de menor calibre, adjacentes à veia jugular. Entretanto em todos os dez animais o trombo limitava-se à veia jugular, não progredindo cranialmente para as veias linguofacial ou maxilar. No terço caudal do pescoço não foram observadas alterações ultra-sonográficas.

Nos animais do grupo controle, o exame ultra-sonográfico realizado no décimo dia depois de induzida a tromboflebite (M10), mostrou a presença do trombo hiperecóico obstruindo completamente o lúmen vascular, com áreas de liquefação hipoecóica, sem sinais de uma progressão cranial ou caudal da área acometida de trombose, quando comparado ao exame realizado com três dias de evolução. Neste momento, nos animais do grupo tratado, não se observou presença de trombos aderidos à parede vascular, caracterizando-se pela presença de fluxo sanguíneo normal confirmando a perviedade da veia jugular. Entretanto, pôde-se observar discreta diminuição da complacência do segmento da veia onde o trombo estava alojado, semelhante ao observado na região da flebotomia para a introdução do cateter de Fogarty, sem interferir no fluxo sanguíneo, sendo ainda possível identificar o espessamento do tecido subcutâneo adjacente a estes segmentos.

O estudo venográfico realizado previamente (M-PRÉ) mostrou o contraste em fluxo linear. Na tromboflebite induzida o estudo venográfico mostrou o impedimento à passagem do contraste através da veia jugular obstruída. Foi possível observar, ainda, a presença de vasos colaterais, na região cervical, fazendo a drenagem lenta e discreta do contraste em seis animais (Fig.4). Após cinco minutos da aplicação do contraste as radiografias mostravam, ainda, a presença do mesmo na região, indicando a dificuldade da drenagem local. Em quatro animais constatou-se o retorno do contraste para a veia linguofacial, entretanto nenhum animal apresentou refluxo para a veia maxilar. 


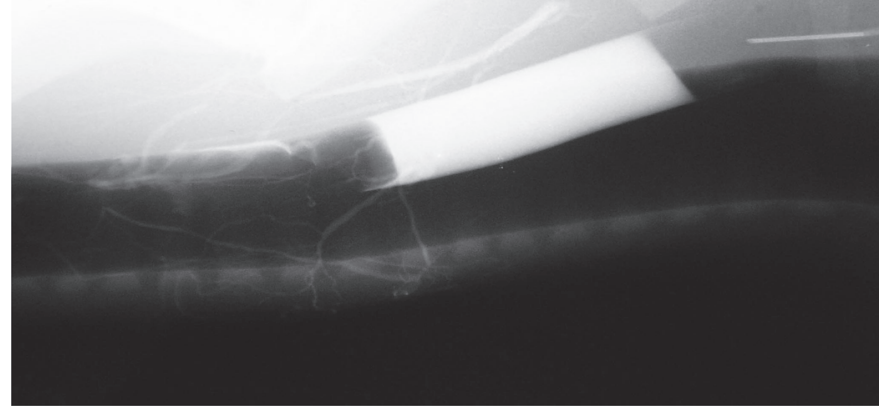

Fig.4. Venografia da jugular direita acometida de trombose (MTI) em animal controle. Observa-se o contraste radiopaco sendo drenado pela circulação colateral, com fluxo sanguíneo no sentido crânio-caudal.

No décimo dia após a indução da tromboflebite, a venografia dos animais controle não apresentou diferenças no crescimento do trombo, assim como na drenagem sanguínea, permanecendo as imagens de forma semeIhante às obtidas no MTI. Nas venografias dos animais do grupo tratamento o contraste fluiu rápido e facilmente através do vaso pérvio, apresentando um traçado linear delgado, no sentido do fluxo sanguíneo. Na radiografia com garroteamento da jugular pôde-se observar a veia totalmente distendida e preenchida pelo contraste, sem sinais de trombos aderidos à parede vascular. (Fig.4)

\section{DISCUSSÃO}

Em humanos as principais decorrências das tromboflebites são as embolias pulmonares, que levam à hipertensão pulmonar e, na seqüência, à morte dos pacientes (Joffe \& Goldhaber 2002), que apresentam intensas alterações clínicas. Apesar da embolia pulmonar fatal ser rara nos eqüinos, uma seqüela mais comumente relatada é a formação de abscessos pulmonares e pneumonia, devido à migração de êmbolos sépticos (Ettlinger et al. 1992, Colahan et al. 1999, Danetz et al. 2003). Por outro lado, a maioria dos óbitos em eqüinos acometidos de tromboflebite de jugular, ocorre principalmente devido ao edema de cabeça que leva à asfixia e alterações cerebrais. A manutenção da normalidade dos parâmetros clínicos mostrados no experimento deveu-se ao padrão dos animais estudados: hígidos e não portadores de enfermidades predisponentes à tromboflebite jugular como alteração mórbida. Deste modo, a metodologia empregada mostrou-se viável para o estudo da tromboflebite em seus aspectos regionais.

Killewich et al. (1989) mostraram que, em longo prazo, os sintomas decorrentes da obstrução venosa crônica de extremidades estão associados principalmente à insuficiência valvular, aspecto este de maior relevância quando considerada a obstrução residual, tendo em vista que os trombos recanalizados associados às colaterais permitem a drenagem sanguínea. A incompetência valvular ocorre em duas etapas. Inicialmente as veias se dilatam em resposta à obstrução venosa proximal e a incompetência valvular ocorre devido às cúspides das válvulas não serem longas o suficiente para se tocarem. Nesta fase, que ocorre entre o primeiro e segundo mês após a obstrução, o processo é reversível. Mais tarde, as válvulas são completamente destruídas, ocasionando assim a incompetência vascular permanente. A ocorrência de dilatação venosa e edema crônico de cabeça tem sido relatada em diversos casos de eqüinos acometidos de trombose de jugular. Entretanto isto não ocorreu no experimento possivelmente por dois motivos: a trombose induzida foi unilateral, com compensação da drenagem sanguínea cefálica pela veia jugular remanescente e por não ter ocorrido a progressão cranial do trombo. Outro ponto a ser levado em consideração seria o curto período de avaliação destes animais, hipótese desconsiderada com base em outro experimento com eqüinos observados a longo prazo, não havendo alterações clínicas regionais significativas após a remoção da veia jugular (Hussni et al. 2006)

Portanto, o tratamento precoce visa prevenir o aparecimento da insuficiência valvular, que manifesta seus sinais clínicos após períodos em que o animal permanece com a cabeça baixa, como durante a alimentação, assim como após atividade física intensa, em que a pressão venosa central se eleva.

A identificação dos trombos foi evidente aos exames ultra-sonográficos, apresentando-se como massa hipoecóica homogênea dentro do vaso sanguíneo. Estes poderiam ainda ser classificados como não cavitários, em que a estrutura é homogênea, ou cavitários com apresentação heterogênea, com áreas hipoecóicas a anecóicas, representando fluido ou áreas necróticas e hiperecóica representando gás (Gardner et al. 1991). Todavia trombos muito recentes podem ser difíceis de diagnosticar, pois a sua ecogenicidade é semelhante à do sangue, e nesses casos a técnica de compressão com o transdutor, sobre o vaso acometido auxilia a distinguir os trombos agudos (Raghavendra et al. 1986), aspecto confirmado neste trabalho. A utilização do ultra-som com "ecodopler" facilitaria ainda mais o diagnóstico (Maffei et al. 2000). Uma vez estabelecida a obstrução venosa aguda, o trombo pode propagar-se, embolizar à distância, ser destruído pelo sistema fibrinolítico ou organizar-se, este último fato observado nos animais do grupo controle.

Para a interpretação da venografia existem critérios bem definidos como: a avaliação da perviedade; a presença ou ausência de imagens valvulares; regularidade do trajeto venoso, do calibre e do contorno das veias; presença ou ausência de circulação colateral e a velocidade de enchimento ou esvaziamento da substância de contraste no sistema venoso (Maffei et al. 2002). A técnica de venografia aplicada no experimento permitiu a avaliação de todos os critérios citados acima, mostrando, portanto, ser um método confiável para avaliação das veias jugulares de eqüi- 
nos, especialmente quando é necessário observar a circulação colateral, tendo em vista que a ultra-sonografia na escala de cinza não permite a observação desses pequenos vasos, devendo-se utilizar o ultra-som colorido.

Conforme observado, vasos colaterais se abrem rapidamente ao redor da área de oclusão, permitindo uma passagem imediata para o sangue proveniente da extremidade obstruída. Em outras espécies o fluxo de drenagem pode permanecer reduzido por até um ano após a oclusão. A extensão da trombose em pacientes humanos pode ocorrer até 30 a 180 dias após a oclusão inicial (Killewich et al. 1989).

Em trabalhos experimentais, a venografia é o método mais preciso para o diagnóstico da trombose venosa (Gaitini et al. 1988). No entanto, nos pacientes gravemente acometidos de trombose, especialmente aqueles com edema de pescoço e cabeça, fica difícil o acesso à veia para a injeção do contraste. Os contrastes à base de iodo podem, ainda, causar reações de hipersensibilidade, nefrotoxicidade e flebite química, podendo agravar a trombose preexistente (Appelman et al. 1987, Joffe \& Goldhaber 2002, Torrance 2004), alterações estas não observadas.

A remoção do trombo com o cateter de Fogarty mostrou ser eficiente e isenta de complicações como a perfuração vascular e a formação de fístula artério-venosa. A possível lesão endotelial nos segmentos venosos onde o baIão foi expandido não pôde ser avaliada. Esta alteração da parede vascular já foi comprovada por outros autores que demonstraram não somente lesão endotelial, mas também na musculatura lisa vascular, distúrbio desencadeado especialmente pela hiper-distensão do balão (Barone et al. 1989). Foi demonstrado que o próprio contato prolongado do trombo com a parede vascular lesa o endotélio, portanto as mais modernas técnicas de desobstrução, associadas a cateteres de micro-fragmentação dos trombos, que tentam minimizar os danos à parede vascular, devem ser empregadas de maneira precoce (Bush et al. 2004). O prazo estabelecido de 72 horas para a desobstrução da veia jugular está de acordo com achados (Kawai et al. 2003) que determinaram este prazo limite para a desobstrução de auto-enxertos venosos em cães, especialmente objetivando a preservação do endotélio.

Evidencias da importância da utilização da heparina no tratamento inicial da trombose venosa está bem estabelecida em animais e humanos (Prandoni 2001). Contudo a heparina parece apresentar melhores resultados na prevenção da trombose no sistema arterial do que no sistema venoso (Hupkens \& Cooley 1997). A utilização e a posologia da heparina no período pós-operatório foram baseadas na descrição inibitória desta na recorrência da trombose (Moore \& Hincliff 1994, Colomina et al. 2000) sendo esta a base para argumentar-se que a heparina contribuiu para a manutenção da perviedade das veias após a trombectomia em questão.

A menor distensão vascular observada nos exames ultra-sonográficos dos animais do grupo tratamento, nos segmentos em que ocorreram a trombose e a flebotomia para introduzir-se o cateter de Fogarty, deveu-se provavelmente à agressão cirúrgica, levando à formação de tecido conjuntivo denso perivascular e ainda à hiperplasia da camada íntima observada após episódios trombóticos. Sigel et al. (1994) observaram o espessamento da parede das veias jugulares de suínos, após a indução da trombose, sendo que no décimo quarto dia foi evidente a maior deposição de matriz extracelular, especialmente colágeno, na parede vascular. Os mesmos autores sugerem que o enrijecimento da parede vascular somente ocorre quando a metodologia aplicada na indução dos trombos apresenta um estímulo trombogênico extenso.

Em humanos estudados por Cronan \& Leen (1989), $50 \%$ dos pacientes demonstraram alterações ultrasonográficas após seis meses do episódio trombótico. Esses autores constataram, ainda, que a idade dos pacientes, a área do trombo e o número de trombos influenciam na recuperação das condições normais do sistema venoso, e que em pacientes jovens a recanalização venosa parece ser mais eficiente. Considera-se, porém, que os animais utilizados neste experimento não portavam enfermidades predisponentes a tromboflebites.

No décimo dia após a indução da tromboflebite jugular os animais do grupo controle apresentaram imagens angiográficas muito semelhantes às do momento da indução, indicando que períodos maiores de observação seriam necessários para detectarem-se diferenças evidentes no fluxo sanguíneo.

No grupo tratado a imagem angiográfica mostrou a perviedade total da veia jugular indicando que a técnica cirúrgica da trombectomia com cateter de Fogarty foi eficiente e a terapia pós-operatória adequada na prevenção da recidiva da trombose.

\section{CONCLUSÕES}

O modelo experimental de indução da trombose da veia jugular de eqüinos foi eficiente para a proposta em questão.

A desobstrução da veia jugular de eqüinos com a técnica da trombectomia utilizando o cateter de Fogarty foi eficiente e exeqüível, podendo ser empregada em casos de tromboflebite aguda de jugular, em eqüinos.

Novos estudos referentes à tromboflebite de jugular em eqüinos mostram-se necessários quanto aos mecanismos fisiopatológicos dos distúrbios que levam à formação dos trombos e sobre os diferentes procedimentos terapêuticos conservativos e cirúrgicos empregados.

Agradecimentos.- À Fundação de Amparo à Pesquisa do Estado de São Paulo (FAPESP).

\section{REFERÊNCIAS}

Appelman P.T., Jong T.E. \& Lampmann L.E. 1987. Deep venous thrombosis of the leg: US findings. Radiology 163:743-746.

Barone G.W., Conerly M., Farley P.C., Flanagan T.L. \& Kron I.L. 1989. Endothelial injury and vascular dysfunction associated with the Fogarty ballon catheter. J. Vasc. Surg. 9:422-425. 
Bayly W.M. \& Vale B.H. 1982. Intravenous catheterization and associated problems in the horse. Compend. Cont. Educ. Pract. Vet. 4:227-237.

Baxter G.M., Parks A.H. \& Prasse K.W. 1991. Effects of exploratory laparotomy on plasma and peritoneal coagulation/fibrinolysis in horse. Am. J. Vet. Res. 52:1121-1127.

Bush R.L., Lin P.H., Bates J.T., Mureerebe L., Zhou W. \& Lumsden A.B. 2004. Pharmacomechanical thrombectomy for treatment of symptomatic lower extremity deep venous thrombosis: safety and feasibility study. J. Vasc. Surg. 40:965-970.

Colahan P.T., Mayhew I.G., Merrit A.M. \& Moore J.N. 1999. Equine Medicine and Surgery. $5^{\text {th }}$ ed. Mosby, Philadelphia. 2076p.

Colomina M.J., Godet C., Bagó J., Pelissé F., Puig O. \& Villanueva C. 2000. Isolated thrombosis of external jugular vein. Surg. Laparoscop. Endoscop. Percutan. Tech. 10:264-267.

Cronan J.J. \& Leen V. 1989. Recurrent deep venous thrombosis: limitations of US. Radiology 170:739-742.

Danetz J.S., McLafferty R.B., Ayerdi J., Grunero L.A., Ramsey D.E. \& Hodgson K.J. 2003. Selective venography versus nonselective venography before vena cava filter placement: Evidence for more, not less. J. Vasc. Surg. 38:928-934.

Divers T.J. 2003. Prevention and treatment of thrombosis, phlebitis, and laminitis in the horse with gastrointestinal disease. Vet. Clin. North. Am., Equine Pract. 19:779-790.

Dornbusch P.T., Hussni C.A., Thomassian A., Alves A.L.G. \& Nicoletti J.L.M. 2000. Tromboflebite jugular nos eqüinos. Revta. Educ. Cont. CRMV-SP 3(2):47-53.

Ettlinger J.J., Palmer J.E. \& Benson C. 1992. Bacteria found on intravenous catheters removed from horses. Vet. Rec. 130:248-249.

Feuerstein G.Z., Toomey J.R., Valocik R., Koster P., Patel A. \& Blackburn M.N. 1999. An inhibitory anti-factor IX antibody effectively reduces thrombus formation in a rat model of venous thrombosis. Thromb. Haemost. 82:1443-1445.

Gardner S.Y., Reef V.B. \& Spencer P.A. 1991. Ultrasonographic evaluation of horses with thrombophlebitis of the jugular vein: $46 \mathrm{ca}-$ ses (1985-1988). J. Am. Vet. Med. Assoc. 199(3):370-373.

Gaitini D., Kaftori J.K., Menucha P. \& Engel A. 1988. High-resolution real time ultrasonography, diagnosis and follow-up of jugular and subclavian vein thrombosis. J. Ultrasound Med. 7:621-627.

Henke P.K., Wakefield T.W., Kadell A.M., Linn M.J., Varma M.R., Sarkar M., Hawley A., Fowlkes J.B. \& Strieter R.M. 2001. Inteleukin-8 administration enhances venous thrombosis resolution in a rat model. J. Surg. Res. 99:84-91.

Hussni C.A., Dornbusch P.T., Alves A.L.G., Thomassian A., Nicoletti J.L.M., Cillo G.P. \& Vulcano L.C. 2006. Avaliação clínica e angiográfica da vascularização consecutiva à ressecção experimental da jugular de eqüinos. Vet. Zootec., Botucatu, 13(2):163-168.

Hupkens P. \& Cooley B. 1997. Comparison of arterial and venous patency in a rat model of subendotheliaum-stimulated thrombosis. Microsurgery 17:226-229.

Imbault P., Doutremepuich F., Aguejouf O. \& Doutremepuich C. 1996. Antithrombotic effects of aspirirn and LMWH in a laser induced model of arterial and venous thrombosis. Thrombosis Res. 82:469-478.

Jang I.K., Gold H.K., Ziskind A.A., Fallon J.T., Holt R.E., Leinbach R.C., May J.W. \& Collen D. 1989. Differential sensitivity of erythrocyte-rich and platelet-rich arterial thrombi to lysis with recombinant tissue-type plasminogen activator. Circulation 79:920-928.

Joffe H.V. \& Goldhaber S.Z. 2002. Upper-extremity deep vein thrombosis. Circulation 106:1874-1880.

Kawai S., Sasajima T., Satoh K., Inaba M., Azuma N., Yamazaki K. \& Oikawa K. 2003. Biologic degeneration of vein grafts after thrombotic occlusion: thrombectomy within 3 days result in better indices of viability. J. Vasc. Surg. 38:305-312.

Killewich L.A., Bedford G.R., Beach K.W. \& Strandness Jr D.E. 1989. Spontaneous lysis of deep venous thrombi: rate and outcome. J. Vasc. Surg. 9:89-97.

Lin P.H., Chen C., Surowiec S.M., Conklin B., Bush R.L. \& Lumsden A.B. 2001. Evaluation of thrombolysis in a porcine model of chronic deep venous thrombosis: An endovascular model. J. Vasc. Surg. 33:621-627.

Maffei F.H.A., Lastória S., Yoshida W.B. \& Rollo H.A. 2002. Doenças Vasculares Periféricas. $3^{\text {a }}$ ed. Medsi, Rio de Janeiro. 1898p.

Moore R.M. \& Hinchcliff K.W. 1994. Heparin: A review of its pharmacology and therapeutic use in horses. J. Vet. Intern. Med. 8:26-35.

Montenegro M.R. \& Franco M. 1999. Patologia: processos gerais. $4^{\text {a }}$ ed. Atheneu, São Paulo. 320p.

Morris D.D. 1989. Thrombophlebitis in horses: The contribution of hemostatic dysfunction to pathogenesis. Compend. Cont. Educ. Pract. Vet. 11:1386-1394.

Prandoni P. 2001. Heparins and venous thromboembolism: current practice and future directions. Thromb. Haemost. 86:488-498.

Quarmby J., Smith A. \& Collins M. 1996. A model of in vivo human venous thrombosis that confirms changes in the release of specifics soluble cell adhesion molecules in experimental venous thrombogenesis. J. Vasc. Surg. 30:139-147.

Raghavendra B.N., Horii S.C., Hilton S., Subramanyam B.R., Rosen R.J. \& Lam S. 1986. Deep venous thrombosis: Detection by probe compression of veins. J. Ultrasound Med. 5:89-95.

Rollo H.A., Maffei F.H., Yoshida W.B., Lastória S., Curi P.R. \& Mattar L. 1991. Heparin, heparin plus ASA and dipyridamole, and arteriovenous fistula as adjuvant methods to prevent rethrombosis after venous thrombectomy. Experimental study in rabits. Int. Angiol. 10(2):19-25.

Sigel B., Swami V., Can A., Parsons R.E., Golub R.M., Kolecki R. \& Kitamura H. 1994. Intimal hyperplasia producing thrombus organization in an experimental venous thrombosis model. J. Vasc. Surg. 19:350360.

Silveira P.G., Galego G.N., Acampora A.J., Bittencourt A., Kestering D., Philippi F.F. \& Rizzatti J. 2001. Estudo experimental comparativo da eficácia antitrombótica da heparina convencional e da heparina de baixo peso molecular. Acta Cirurg. Bras. 16(4). Disponível em URL http://www.scielo.br

Spurlock S.L. \& Spurlock \& G.H. 1990. Risk factors of catheter-related complications. Compend. Cont. Educ. Pract. Vet. 12:241-248.

Traub-Dargatz J.L. \& Dargatz D.A. 1994. A retrospective study of vein thrombosis in horses treated with intravenous fluid in a veterinary teaching hospital. J. Vet. Intern. Med. 8(4):264-266.

Topper M.J. \& Prasse K.W. 1998. Analysis of coagulation proteins as acute-phase reactants in horse with colic. Am. J. Vet. Res. 59:542-545.

Torrance A.R. 2004. Contrast peripheral phlebography and pulmonary angiography for diagnosis of thromboembolism. Circulation 109:I22I27. Disponível em: URL:http://circ.ahajournals.org

Underwood M.J., More R., Gershlick A.H. \& Bono D.P. 1993. Quantitatifying the effect of locally delivered anticoagulant drugs: modification of an in vivo model of venous thrombosis. J. Vasc. Res. 30:323-326.

Van Zyl W.B., Pretorius G.H., Lamprecht S., Roodt J.P. \& Kotzé H.F. 2000. Platsak, a potent antothrombotic and fibrinolytic protein, inhibits arterial and venous thrombosis in a baboon model. Thrombosis Res. 98(5):435-443.

Warmedam E.P.L. 1998. "Pseudo-catheter-sleeve" sign in the jugular vein of a horse. Vet. Radiol. Ultrasound 39:148-149. 